\title{
High-Intensity Statin Therapy Is "Too Much," Thus Not Indicated for Very Elderly Patients
}

\author{
Ok Sang Lee ${ }^{a, b}$ Jinlong Zhang ${ }^{c}$ Sun-Hoi Jung ${ }^{a}$ Hyang-Sook Kim ${ }^{a}$ \\ Myung-Koo Lee ${ }^{b}$ Hae-Young Lee ${ }^{c}$ \\ a Department of Pharmacy, Seoul National University Hospital, Seoul, South Korea; \\ ${ }^{b}$ College of Pharmacy, Chungbuk National University, Cheongju, South Korea; \\ 'Department of Internal Medicine, Seoul National University Hospital, Seoul, South Korea
}

\section{Keywords}

Statins $\cdot$ Elderly $\cdot$ Cardiovascular disease $\cdot$ Cholesterol $\cdot$ Adverse drug reaction

\begin{abstract}
Purpose: Although moderate- to high-intensity statin therapy is increasingly recommended in cardiovascular disease patients, the efficacy and safety in elderly patients have not been proven clearly. Here, we compare the effect of various-intensity statins between elderly and very elderly patients. Methods: 43,870 patients over 65 years old who were treated with statins were screened using electronic medical record data. Results: We evaluated 451 patients in the elderly group aged 65-74 years and 159 patients in the very elderly group over 75 years old. Baseline cholesterol profiles were similar between the 2 groups, but the 10 year atherosclerotic cardiovascular disease (ASCVD) risk was significantly higher in the very elderly $(20.9 \pm 11.5 \%$ vs. $37.2 \pm 13.6 \%, p<0.001)$. The reduction rate of low-density lipoprotein $(\mathrm{LDL})(-40.2 \pm 21.3 \%$ vs. $-39.3 \pm 21.0 \%, p=0.634)$ and the ratio of target LDL attainment ( 74.2 vs. $79.2 \%, p=0.252$ ) were similar between the 2 groups. Low-intensity statins showed comparable LDL cholesterol reduction with moderate-intensity statins both in the elderly and the very elderly groups. The 10-year ASCVD risk reduction was similar between the 2 groups $(-3.5 \pm 4.9 \%$ vs. $-3.0 \pm 8.4 \%, p=0.480)$, but in the very elderly group, no different ASCVD reduction rate was shown in low- to high-intensity statins $(p=0.784)$. Only the el-
\end{abstract}

Ok Sang Lee and Jinlong Zhang contributed equally to this paper. 
derly group showed a significant correlation $(r=0.112, p=0.017)$ with LDL reduction and 10-year ASCVD risk. Interestingly, the incidence of adverse drug reaction (ADR) was higher in the very elderly group (4.4\%) than in the elderly group (2.7\%) and was more frequent in high-intensity statin therapy. Conclusion: The efficacy of statins in LDL reduction was similar between the elderly and very elderly population. However, the benefit of moderate- to high-intensity statins is limited considering potential ADR. Therefore, the stepwise intensification of statin therapy might be necessary for the very elderly in spite of the higher cardiovascular risk.

(C) 2018 S. Karger AG, Basel

\section{Introduction}

Dyslipidemia is an important risk factor of cardiovascular disease [1, 2]. A $10 \mathrm{mg} / \mathrm{dL}$ increase of total cholesterol was associated with a 9\% increase of 30-year cardiovascular death in the Framingham study [3]. Conversely, reducing plasma low-density lipoprotein (LDL) cholesterol levels by statins remarkably reduced the cardiovascular death both in primary prevention and secondary prevention [4,5]. Following numerous clinical study results, LDL reduction with statin treatment became the cornerstone of lipid-lowering therapy to reduce cardiovascular risk [6-8].

Compared to the previous guidelines developed by the National Cholesterol Education Program Expert Panel [9] and the European Society of Cardiology [10], the recently published 2013 guidelines of the American College of Cardiology and the American Heart Association (ACC-AHA) for the management of cholesterol substantially expanded the number of adults indicated for statin therapy [11-13]. Especially, the new guideline recommends wide use of intensive statin therapy in all patients with an LDL $\geq 190 \mathrm{mg} / \mathrm{dL}$, who also have either diabetes or a 10-year risk of atherosclerotic cardiovascular disease (ASCVD) of 7.5\% or more, as estimated on the basis of new pooled cohort equations [11]. Although it is well known that the prevalence of cardiovascular disease rises markedly with age [14], it is debatable whether it is justified that under the "age-based" strategy in the new ACC-AHA guideline, virtually all men $>65$ years old and women $>75$ years old exceeded the 10-year estimated ASCVD risk of $7.5 \%$ regardless of other risk factors, thus being the indication for intensive statin therapy [13].

Another issue is the paucity of data in very elderly patients over 75 years old. Limited numbers of patients $>75$ years of age were included in statin randomized clinical trials (RCTs). Therefore, the pooled cohort equations are not recommended to inform the 10-year ASCVD risk for those $>75$ years of age [13]. Although a number of data support the use of moderateintensity statin therapy for secondary prevention in individuals with a clinical ASCVD risk $>7.5 \%$, it is unclear if it should be initiated with high-intensity statins in individuals $>75$ years of age. As a whole, we have only limited data regarding the potential ASCVD risk reduction benefits and the risk of adverse effects of high-intensity statin therapy for older individuals.

Here, we compare the efficacy and safety of high-intensity statin therapy in elderly (65-74 years of age) and very elderly ( $\geq 75$ years of age) Korean patients. In order to overcome the limitation of RCT data of the elderly and very elderly population, we investigated "real world" data by reviewing electronic medical record data of 43,870 patients over 65 years old who were treated with statins. 
Lee et al.: High-Intensity Statin Therapy Is "Too Much," Thus Not Indicated for Very Elderly Patients

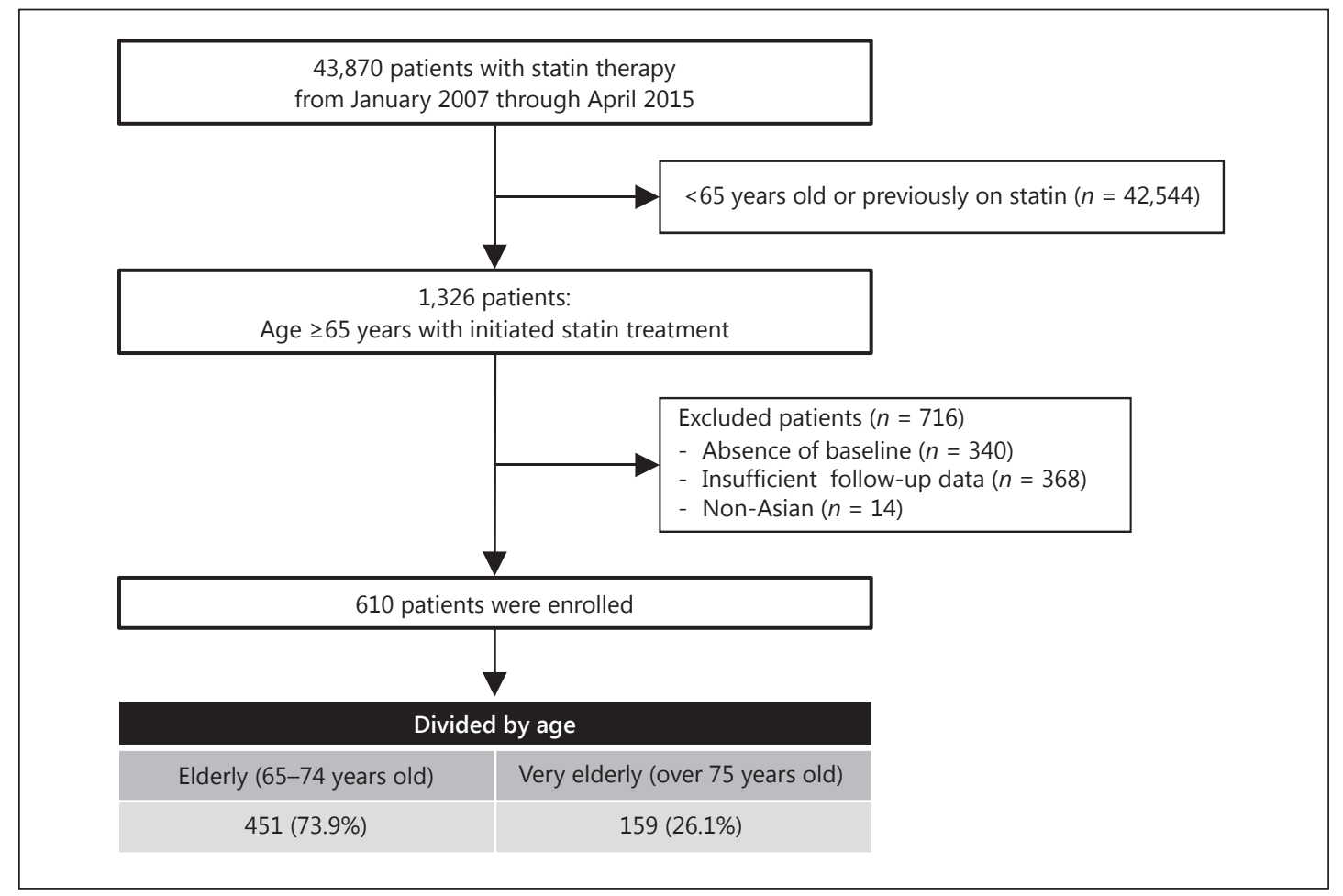

Fig. 1. Study flow.

\section{Methods}

\section{Patient Selection}

We reviewed the electronic medical records of all patients who were prescribed statins in Seoul National University Hospital (SNUH) from January 1, 2007, through April 30, 2015. We identified 43,870 patients $>65$ years old who were treated with statins. Among them, we selected 610 patients who had newly initiated statin treatment and had baseline data as well as follow-up data. Patient selection flow is summarized in Figure 1.

Patients were treated with statins including atorvastatin, fluvastatin, lovastatin, pitavastatin, pravastatin, rosuvastatin, and simvastatin or a statin combination (ezetimibe/simvastatin). The intensity of statins was categorized as per previous scientific statements. We collected clinical data including age, gender, smoking status, blood pressure, and presence of cardiovascular disease, diabetes, or stroke. We also collected laboratory test results: total cholesterol, triglycerides, high-density lipoprotein (HDL) cholesterol, LDL cholesterol, glucose, glycated hemoglobin $\left(\mathrm{HbA}_{1 \mathrm{c}}\right)$, creatinine, sodium, potassium, uric acid, aspartate aminotransferase or alanine aminotransferase, and creatine phosphokinase.

Comparison groups were divided into elderly (65-74 years of age) and very elderly ( $\geq 75$ years of age) patients. Treatment was divided into high intensity (estimated LDL lowering $\geq 50 \%$ ), moderate intensity (estimated LDL lowering 30-50\%), and low intensity (estimated LDL lowering $<30 \%$ ) by the statin name and dose based on the guidelines of the 2013 ACC/AHA guideline [13]. This study was approved by SNUH Institutional Review Board (IRB\# H-1409-118-611).

\section{Efficacy and Safety Evaluation}

The effects of statin therapy were evaluated by measuring the LDL cholesterol reduction rate from baseline to 3 time points of follow up (2-6 months, 6-18 months, and 19-30 months). Although the pooled cohort equations are not recommended to inform cardiovascular risk for those $\geq 75$ years of age, we calculated the ASCVD risk score to evaluate the risk reduction by statin therapy by using patients' information on race, age, gender, blood pressure, total cholesterol, HDL cholesterol, diabetes, and smoking status [13]. As the 10-year ASCVD risk was calculated up to a maximum of 79 years, we counted the age as 79 years if the patients were older than 79 years. 
Table 1. Baseline characteristics

\begin{tabular}{|c|c|c|c|}
\hline & $\begin{array}{l}\text { Elderly } \\
(n=451)\end{array}$ & $\begin{array}{l}\text { Very elderly } \\
(n=159)\end{array}$ & $\begin{array}{l}p \\
\text { value }\end{array}$ \\
\hline Female gender, \% & 62.3 & 56.0 & 0.16 \\
\hline Current smoker, \% & 6.9 & 4.4 & 0.268 \\
\hline Hypertension, \% & 74.3 & 86.8 & 0.001 \\
\hline \multicolumn{4}{|c|}{ Previous cardiovascular disease/ } \\
\hline diabetes mellitus, \% & 51.9 & 51.6 & 0.946 \\
\hline Diabetes mellitus, $\%$ & 36.4 & 28.9 & 0.09 \\
\hline \multicolumn{4}{|l|}{ Statin potency, \% } \\
\hline High & 18.4 & 18.2 & 0.866 \\
\hline Moderate & 74.1 & 75.5 & \\
\hline Low & 7.5 & 6.3 & \\
\hline $\mathrm{SBP}, \mathrm{mm} \mathrm{Hg}$ & $131.1 \pm 16.1$ & $134.7 \pm 17.5$ & 0.020 \\
\hline Total cholesterol, mg/dL & $215.7 \pm 41.3$ & $210.2 \pm 38.3$ & 0.146 \\
\hline Triglycerides, mg/dL & $147.0 \pm 77.6$ & $153.5 \pm 101.6$ & 0.401 \\
\hline $\mathrm{HDL}, \mathrm{mg} / \mathrm{dL}$ & $51.1 \pm 13.1$ & $50.9 \pm 17.3$ & 0.879 \\
\hline $\mathrm{LDL}, \mathrm{mg} / \mathrm{dL}$ & $142.4 \pm 36.1$ & $137.0 \pm 32.6$ & 0.099 \\
\hline BUN, mg/dL & $16.2 \pm 5.4$ & $17.5 \pm 5.7$ & 0.013 \\
\hline Creatinine, $\mathrm{mg} / \mathrm{dL}$ & $0.92 \pm 0.46$ & $1.03 \pm 0.66$ & 0.034 \\
\hline AST, IU/L & $23.0 \pm 8.04$ & $24.4 \pm 10.2$ & 0.115 \\
\hline ALT, IU/L & $23.6 \pm 13.8$ & $22.7 \pm 12.7$ & 0.524 \\
\hline Glucose, mg/dL & $112.6 \pm 37.2$ & $111.5 \pm 35.2$ & 0.795 \\
\hline $\mathrm{CPK}, \mathrm{IU} / \mathrm{L}$ & $98.9 \pm 49.3$ & $84 \pm 28.3$ & 0.020 \\
\hline 10-year ASCVD risk, \% & $20.9 \pm 11.5$ & $37.2 \pm 13.6$ & $<0.001$ \\
\hline ASCVD risk $>7.5 \%, \%$ & 91.6 & 98.7 & 0.002 \\
\hline
\end{tabular}

SBP, systolic blood pressure; HDL, high-density lipoprotein; LDL, low-density lipoprotein; BUN, blood urea nitrogen; AST, aspartate aminotransferase; ALT, alanine aminotransferase; CPK, creatine phosphokinase; ASCVD, atherosclerotic cardiovascular disease.

Table 2. Change of cholesterol profiles after 6 months' statin treatment

\begin{tabular}{lccc}
\hline & $\begin{array}{l}\text { Elderly } \\
(n=451)\end{array}$ & $\begin{array}{l}\text { Very elderly } \\
(n=159)\end{array}$ & $p$ value \\
\hline LDL cholesterol & & & \\
$\quad$ Baseline, mg/dL & $142.4 \pm 36.1$ & $137.0 \pm 32.6$ & 0.099 \\
$\quad 6$ months (LOCF), mg/dL & $81.0 \pm 28.6$ & $79.8 \pm 26.2$ & 0.653 \\
$\quad$ Reduction, \% & $-40.2 \pm 21.3^{*}$ & $-39.3 \pm 21.0^{*}$ & 0.634 \\
Total cholesterol & & & \\
$\quad$ Baseline, mg/dL & $215.7 \pm 41.3$ & $210.2 \pm 38.3$ & 0.146 \\
$\quad 154.4 \pm 32.7$ & $144.97 \pm 30.2$ & 0.002 \\
$\quad$ Reduction, \% & $-27.2 \pm 15.3^{*}$ & $-29.6 \pm 15.2^{*}$ & 0.103 \\
HDL cholesterol & & & \\
$\quad$ Baseline, mg/dL & $51.1 \pm 13.1$ & $50.9 \pm 17.3$ & 0.879 \\
$\quad 6$ months (LOCF), mg/dL & $53.0 \pm 13.0$ & $49.9 \pm 14.3$ & 0.013 \\
$\quad$ Reduction, \% & $5.6 \pm 23.4^{*}$ & $1.3 \pm 22.9^{* *}$ & 0.044 \\
Triglycerides & & & \\
$\quad$ Baseline, mg/dL & $147.0 \pm 77.6$ & $153.5 \pm 101.6$ & 0.401 \\
$\quad$ months (LOCF), mg/dL & $119.6 \pm 60.3$ & $115.9 \pm 56.0$ & 0.499 \\
$\quad$ Reduction, \% & $-10.4 \pm 40.7^{*}$ & $-14.1 \pm 38.0^{*}$ & 0.321 \\
\hline
\end{tabular}

LDL, low-density lipoprotein; LOCF, last observation carried forward; HDL, high-density lipoprotein. $p$ values are expressed from paired $t$ test. ${ }^{*} p<0.001,{ }^{* *} p=0.489$. 
Lee et al.: High-Intensity Statin Therapy Is "Too Much," Thus Not Indicated for Very Elderly Patients

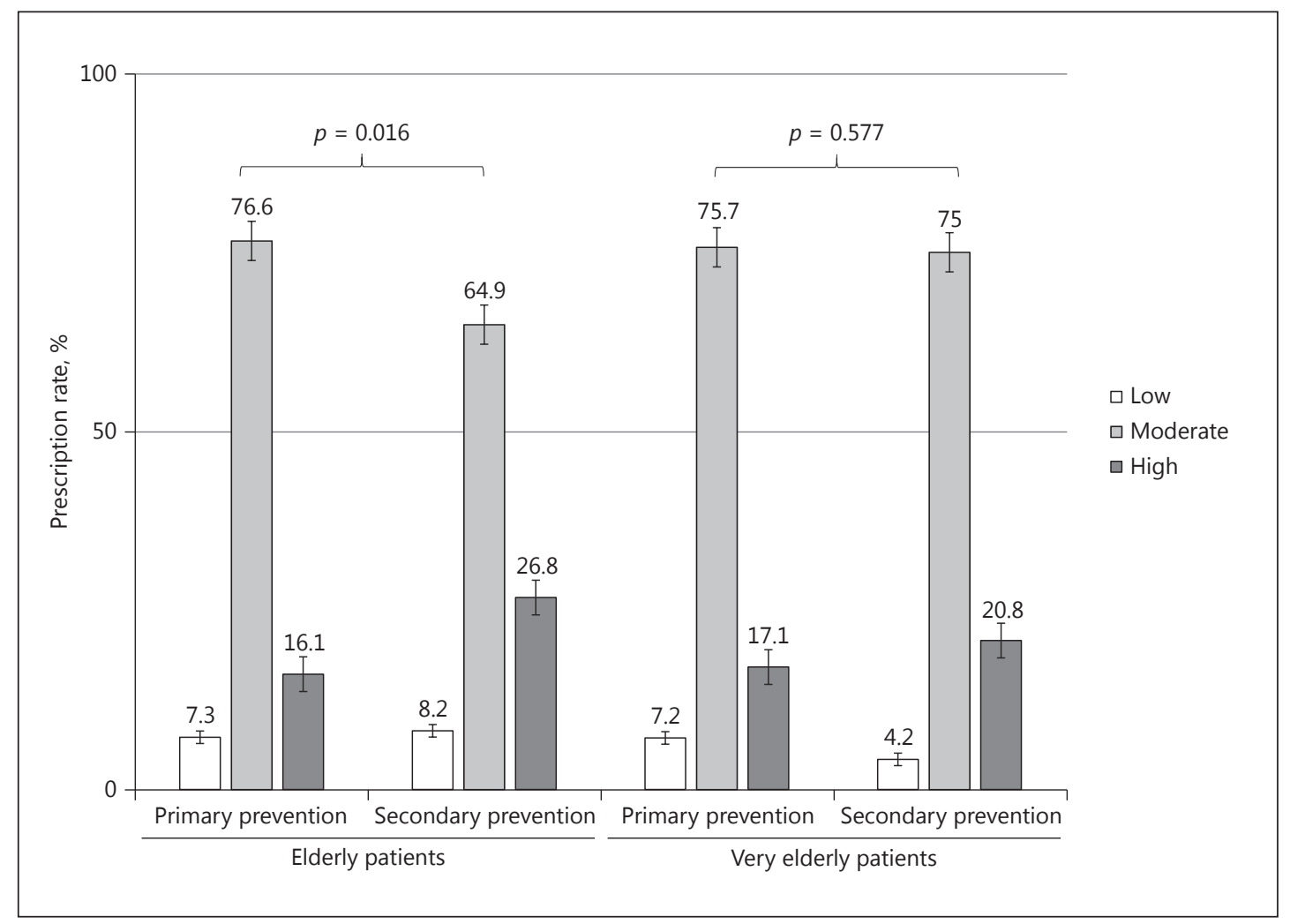

Fig. 2. Patterns of statin prescription according to treatment purpose. $p$ values were computed from the $\chi^{2}$ test.

We evaluated adverse drug reactions (ADRs) of hepatotoxicity, myopathy, new-onset diabetes mellitus, and discontinuation due to patients' subjective discomfort. Hepatotoxicity was defined as a new elevation of aspartate aminotransferase or alanine aminotransferase 3 times higher than normal [15]. Myopathy was defined as an elevation of creatine phosphokinase 5 times higher than normal or myalgia requiring statin discontinuation [16]. New-onset diabetes mellitus was defined as a new clinical diagnosis of diabetes mellitus or fasting blood glucose $>126 \mathrm{mg} / \mathrm{mL}$ [17].

\section{Statistical Analysis}

LDL reduction and 10-year ASCVD risk reduction were described as mean \pm SD, and we analyzed average differences in 2 groups (age) by the Student $t$ test and average differences in 3 groups (statin intensity) by one-way ANOVA. The rates of taking statin and occurring adverse drug event were described as percentages and analyzed by the $\chi^{2}$ test. The change between baseline and last observation carried forward (LOCF) value was compared with the paired $t$ test. The relation between LDL reduction rate and 10 -year ASCVD risk reduction was analyzed by correlation analysis. Null hypotheses of no difference were rejected if $p$ values were $<0.05$. Data was analyzed by SPSS (version 22.0).

\section{Results}

\section{Patient Characteristics and Pattern of Statin Prescription}

Among 43,870 elderly patients, 451 patients of the elderly group aged 65-74 years and 159 patients of the very elderly group over 75 years were identified. The proportion of patients with cardiovascular disease or diabetes mellitus was approximately half, which was 
Lee et al.: High-Intensity Statin Therapy Is "Too Much," Thus Not Indicated for Very Elderly Patients

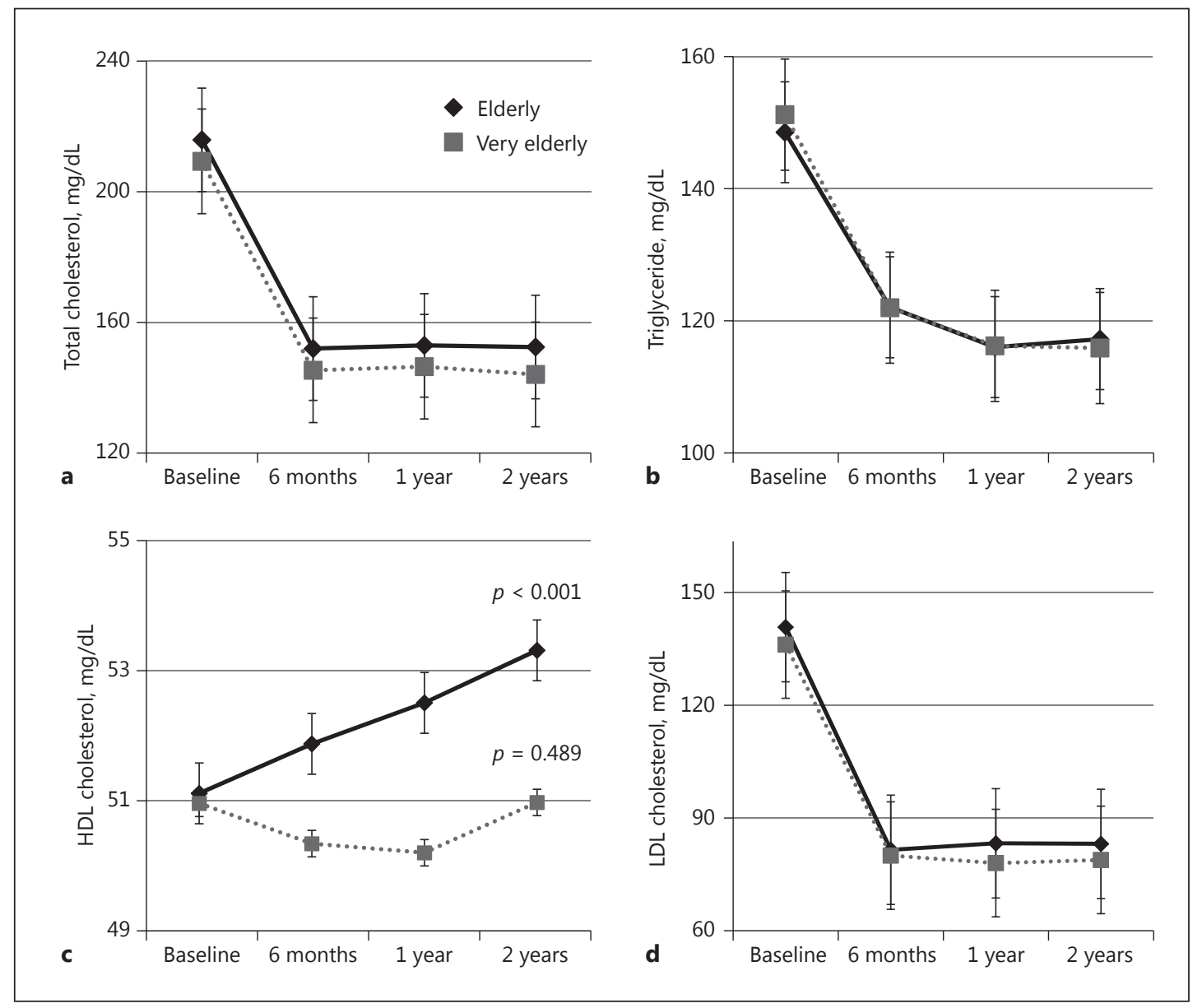

Fig. 3. Changes in cholesterol profile after statin treatment: total cholesterol (a), triglyceride (b), HDL cholesterol (c), and LDL cholesterol (d).

similar between the 2 groups ( $p=0.946$ ). However, the estimated 10-year ASCVD risk was nearly double in the very elderly group (Table 1 ).

Baseline cholesterol profiles were similar between the 2 groups. Although more than half of the patients belonged to the indication of high-intensity statins, only $18.4 \%$ of the patients were actually treated with high-intensity statins. In the elderly group, the prescription rate of high-intensity statins was significantly higher in case of the secondary prevention purpose (16.1 vs. $26.8 \%, p=0.016$ ); however, the prescription rate of high-intensity statins between primary and secondary prevention was not significantly different in the very elderly group (Fig. 2).

\section{Comparison of the Treatment-Attained Value between the 2 Groups}

The follow-up rates were 6 months (elderly: $98.0 \%$, very elderly: 99.4\%), 1 year (elderly: $65.0 \%$, very elderly: $61.6 \%$ ), and 2 years (elderly: $39.7 \%$, very elderly: $39.6 \%$ ).

Total cholesterol, triglyceride, and LDL cholesterol levels were significantly decreased by $27.2,10.4$, and $40.2 \%(p<0.001, p<0.001, p<0.001)$ in the elderly group and by 29.6, 14.1, and $39.25 \%(p<0.001, p<0.001, p<0.001)$ in the very elderly group, respectively, during 2 years' statin treatment. However, HDL cholesterol levels were significantly increased only in the elderly group by $5.6 \%(p<0.001)$, compared to the very elderly group $(1.3 \% ; p=0.489)$. 
Lee et al.: High-Intensity Statin Therapy Is "Too Much," Thus Not Indicated for Very Elderly Patients

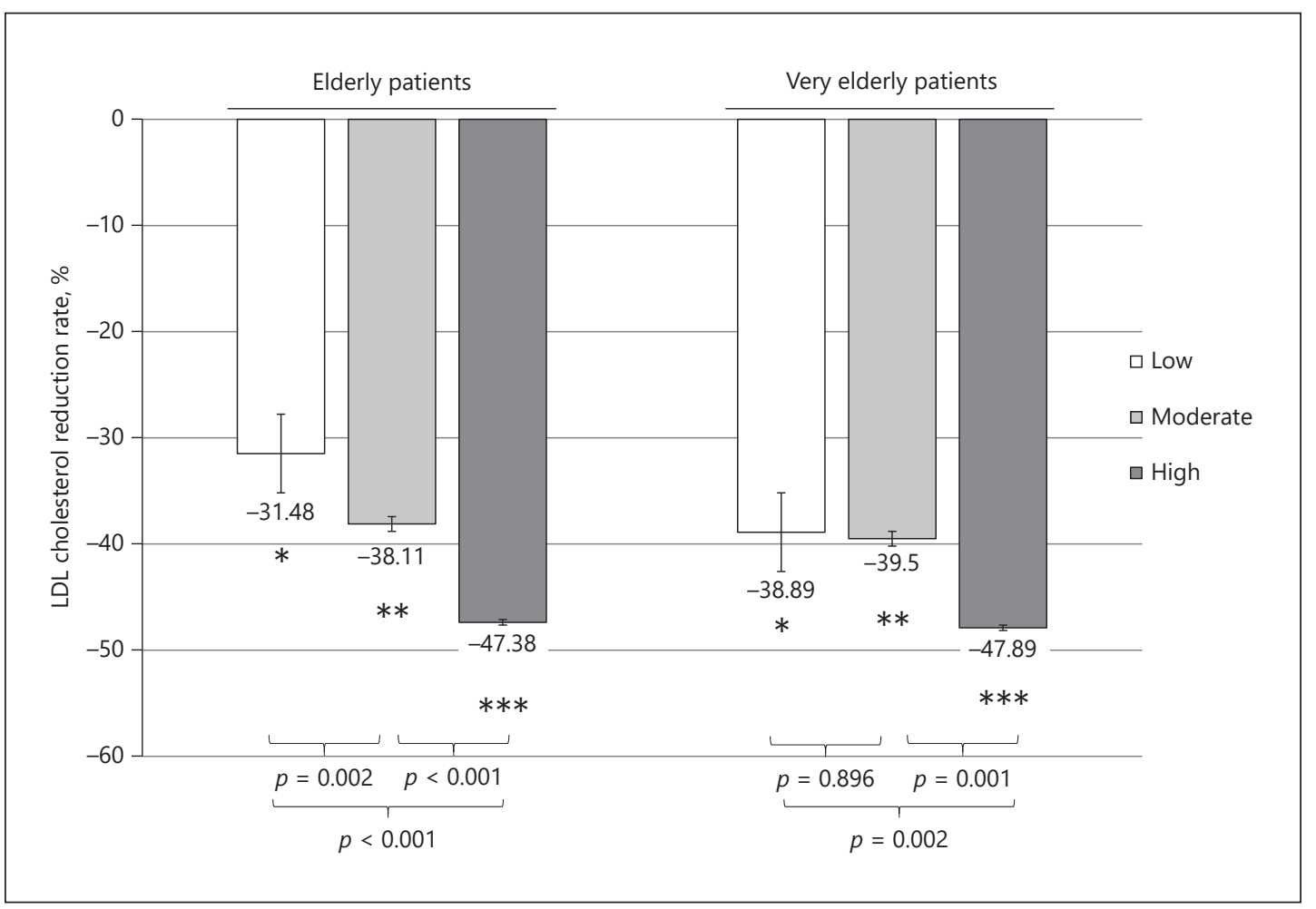

Fig. 4. LDL cholesterol reduction stratified by statin intensity. $p$ values were computed from independent $t$ test between the elderly and the very elderly groups. ${ }^{*} p=0.129,{ }^{* *} p=0.560,{ }^{* * *} p=0.909$.

When comparing the 2 groups, the significant difference was observed in LOCF of total cholesterol $(p=0.002)$ and HDL cholesterol ( $p=0.013)$ but not of LDL cholesterol ( $p=0.653)$ (Table 2; Fig. 3).

Next, LDL cholesterol reduction stratified by statin intensity between the elderly and the very elderly groups was compared. In the elderly group, there was a clear difference in LDL cholesterol reduction according to statin intensity (overall, $p<0.001$; low vs. moderate, $p=$ 0.002 ; moderate vs. high, $p<0.001$ ). However, in the very elderly group, low-intensity statins showed comparable LDL cholesterol reduction with moderate-intensity statins (overall, $p=$ 0.002; low vs. moderate, $p=0.896$; moderate vs. high, $p=0.001$ ) (Fig. 4).

We also compared the target LDL goal achievement rate (\%) based on the statin strength in both age groups. Target LDL was set based on the expected risk according to the ATP III guideline [18]. Overall, the mean target LDL goal achievement rates were $74.7 \%$ in the elderly group and $79.2 \%$ in the very elderly group $(p=0.252)$. The relation between statin intensity and the target LDL goal achievement rate was only significant in the elderly group ( $p=0.024)$, and there was no significant dose response in the very elderly group $(p=0.265)$ (Table 3 ).

\section{Effect of Statins on ASCVD Risk Reduction between the 2 Groups}

We investigated the effect of statin treatment by using the 10-year ASCVD risk score as a surrogate marker of cardiovascular risk reduction. Following statin treatment, the 10-year ASCVD risk score significantly decreased in both groups by 3.5 and $3.0 \%$, respectively $(p<$ $0.001, p<0.001$ ) (Fig. 5a). There was no significant difference in the ASCVD risk reduction between the 2 groups ( $p=0.475$ ), and the ASCVD risk was continuously far higher in the very elderly group throughout the follow-up period. 
Lee et al.: High-Intensity Statin Therapy Is "Too Much," Thus Not Indicated for Very Elderly Patients

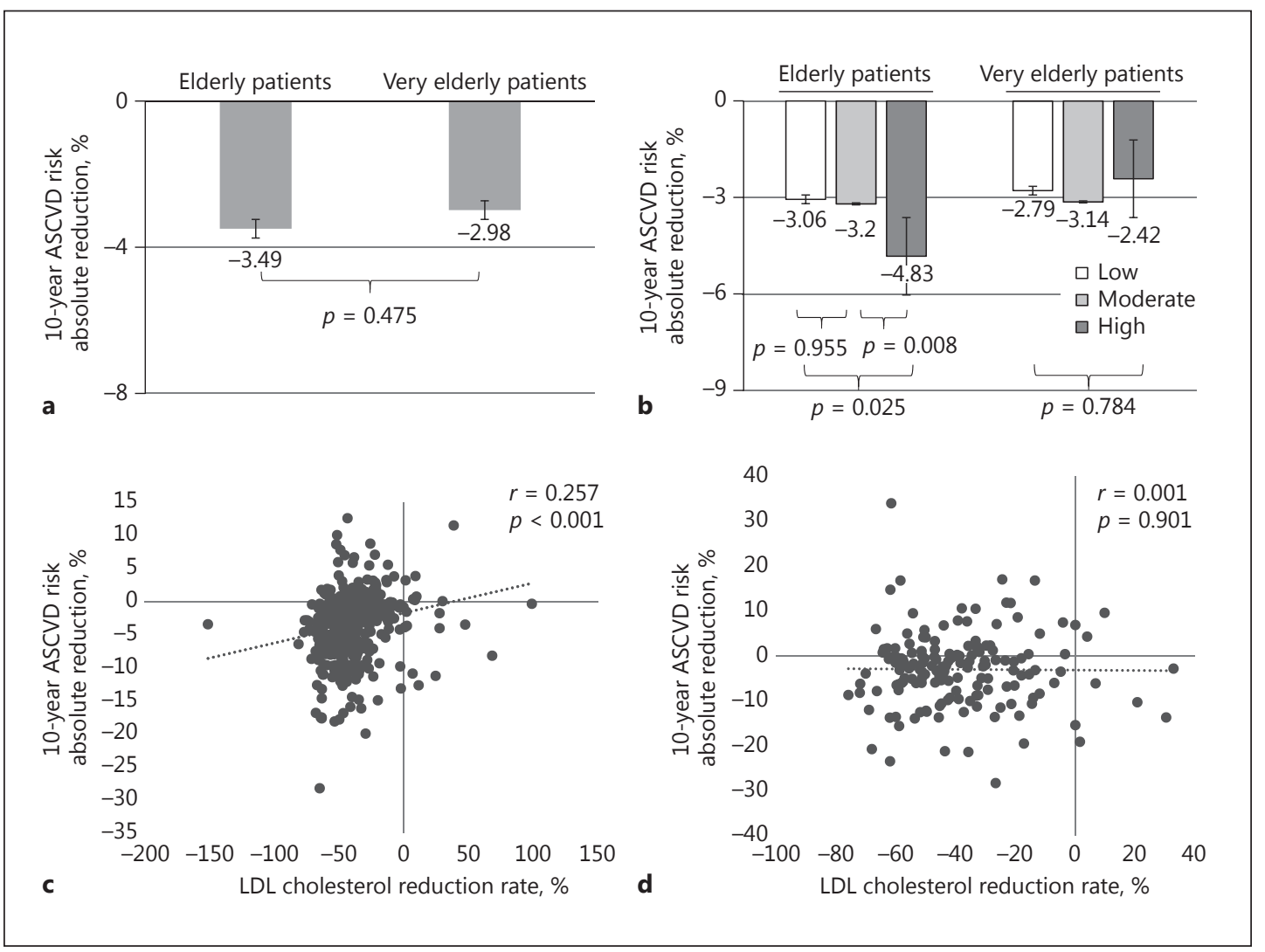

Fig. 5. Ten-year atherosclerotic cardiovascular disease (ASCVD) risk score reduction following statin treatment. a Overall ASCVD risk reduction in the elderly and very elderly patients. The $p$ value was computed from paired $t$ test. b ASCVD risk reduction according to statin intensity. c Correlation between LDL cholesterol and ASCVD risk reduction in the elderly group. $\mathbf{d}$ Correlation between LDL cholesterol and ASCVD risk reduction in the very elderly group.

Table 3. Target LDL goal achievement rate $(\%)$ between the 2 groups stratified by statin potency

\begin{tabular}{llll}
\hline Statin intensity & Elderly & Very elderly & $p$ value \\
\hline Low & 664.7 & 670.0 & 0.756 \\
Moderate & 673.1 & 677.5 & 0.340 \\
High & 685.5 & 689.7 & 0.576 \\
Total & 674.7 & 679.2 & 0.252 \\
$p$ value & 0.024 & 0.265 & \\
\hline
\end{tabular}

Table 4. Incidence of statinassociated adverse drug reactions (ADRs) stratified by statin potency

\begin{tabular}{lccc}
\hline Potency & ADR, $n$ & Total, $n$ & $\%$ \\
\hline Low & 1 & 44 & 2.2 \\
Moderate & 11 & 454 & 2.4 \\
High & 7 & 112 & 6.3 \\
\hline
\end{tabular}


Fig. 6. Incidence of adverse drug reaction following statin treatment. Hepatotoxicity was defined as a new elevation of aspartate aminotransferase or alanine aminotransferase 3 times higher than normal [13]. Myopathy was defined as an elevation of creatine phosphokinase 5 times higher than normal or myalgia requiring statin discontinuation [14]. Newonset diabetes mellitus was defined as a new clinical diagnosis of diabetes mellitus or fasting blood glucose $>126 \mathrm{mg} / \mathrm{mL}$ [15].
Lee et al.: High-Intensity Statin Therapy Is "Too Much," Thus Not Indicated for Very Elderly Patients

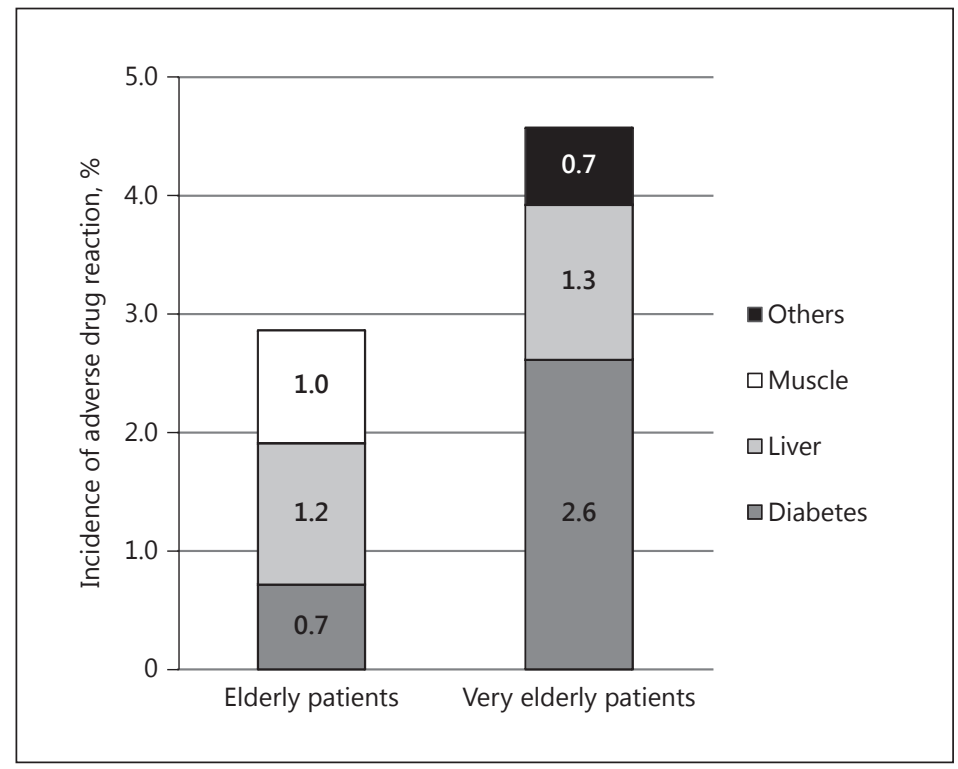

Then, we evaluated the impact of statin intensity in ASCVD risk reduction. In the elderly group, more ASCVD risk reduction was shown in the patients with high-intensity statins compared to those with moderate-intensity statins $(p=0.008)$. However, there were no differences between patients with moderate-dose statins and those with low-dose statins $(p=0.955)$. In the very elderly group, no differences in ASCVD reduction rate were shown among the 3 statin dose groups $(p=0.784)$ (Fig. 5b). Similarly, LDL reduction was significantly correlated with 10-year ASCVD in the elderly group $(r=0.257, p<0.001)$, whereas the very elderly group showed an insignificant correlation ( $r=0.001, p=0.901)$ (Fig. 5c, d).

\section{Presence of ADR between the 2 Groups}

We evaluated the incidence of ADR after statin therapy in both groups. High-intensity statins showed higher ADR $(n=7,6.3 \%)$, compared to low-intensity statins $(n=1,2.3 \%)$ and moderate-intensity statins $(n=1,2.4 \%)(p=0.107$; Table 4$)$. Types of ADRs $(n=19)$ were abnormality of liver $(n=7)$ and muscle $(n=4)$, new-onset diabetes mellitus $(n=7)$, and discontinued therapy due to complaint $(n=1)$.

Although there was no statistical significance due to the small number of adverse events, the incidence rate of adverse events was higher in the very elderly group $(n=7,4.4 \%)$ than in the elderly group $(n=12,2.7 \%)(p=0.292)$. In particular, the risk of new-onset diabetes mellitus was five-fold higher in the very elderly group $(n=4,2.6 \%)$ than in the elderly group $(n=3,0.7 \%)$, although there was no significant difference due to the small number of ADRs (Fig. 6).

\section{Discussion}

The risk of cardiovascular disease is increasing with age, which becomes the rationale of aggressive treatment of dyslipidemia in elderly patients. However, there are only limited data evaluating the impact of aggressive statin therapy in very elderly patients over 75 years old. Moreover, in most RCTs, the enrollment of patients aged $>75$ years is limited (only $2 \%$ in studies published during 1966-1990 and 9\% during 1991-2000) [19]. In addition, it is not 
likely that clinical trials that evaluate statin effects in the elderly population will be proceeded in the near future. Therefore, we performed this retrospective study to investigate the role of aggressive statin treatment in the very elderly population. Similar to the difficulty in clinical trials, among 43,870 patients over 65 years old who were treated in our hospital for 5 years, we could only find 610 patients who were eligible for the analysis. They had newly initiated statin treatment and had baseline data as well as follow-up data.

Our results indicated several important findings. First, even though most of the patients belonged to the high-risk category either by ATP III criteria or by the new ACC-AHA guideline, only a minority of the patients was actually treated with high-intensity statins in the real world situation. Second, notwithstanding the lower intensity than the intensity recommended by the guidelines, statin treatment resulted in a LDL cholesterol reduction of more than $40 \%$ in most patients. Third, high-intensity statins exerted sufficient LDL cholesterol-lowering effects in the very elderly group. Fourth, the target LDL goal achievement rate increased significantly according to statin intensity only in the elderly group compared to the insignificant result in the very elderly group. Fifth, cardiovascular risk quantified by the 10-year ASCVD risk showed a modest reduction in both groups. Lastly, the incidence of ADR was about twice higher in the very elderly group compared to the elderly group, which was more frequent in high-intensity statin therapy. These findings suggest that the benefit of moderateto high-intensity statins might be limited in the very elderly group considering the smaller reduction of cardiovascular risk and higher incidence of ADR.

These findings have important clinical implications considering that under the "agebased" strategy in the new ACC-AHA guideline, virtually all men $>65$ years old and women $>75$ years old exceed the 10-year estimated ASCVD risk 7.5\% regardless of other risk factors. Thus, intensive statin therapy is indicated for those patients. [20]. In a study, more than $40 \%$ of $\geq 65$-year-old Australians were taking statin, and the proportion of statin usage was increasing with age. In this study, one-third of the overall population older than 75 years was treated by moderate- to high-intensity statins [21]. Furthermore, the proportion of high-risk patients, the frequency of use of more potent statins, and the rate of LDL cholesterol goal attainment were significantly greater in the Korean subjects than those observed in the other Asian populations [22].

Of course the benefit of moderate- to high-intensity statin for secondary prevention seems clear. However, their role in primary prevention is limited [23] and still uncertain. Especially the role of statin in the primary prevention of cardiovascular disease in older patients is unclear. However, according to a 2012 study from the USA, the ratio of those treated for primary prevention to those treated for secondary prevention was significantly greater in patients aged $\geq 80$ years than in those aged 55-65 years [24]. A similar preponderance was reported in an Italian population aged $>75$ years, two-thirds of which had an indication for primary prevention [24]. A meta-analysis study showed that statin therapy decreased the risk of myocardial infarction by $39.4 \%$ and the risk of stroke by $23.8 \%$ in elderly patients with high cardiovascular risk who did not have a history of cardiovascular disease [25]. Also, the Cholesterol Treatment Trialists' collaboration study showed that highdose statins in the very elderly group had a more significant effect. And the risk ratio was decreased with decreasing LDL cholesterol reduction as well as elderly group, which demonstrated the benefit of high-intensity statins [26]. However, the potential risks for the elderly, such as the decreased life expectancy, increased comorbidities, risk of polypharmacy, and increased risk of adverse reactions, should be balanced with the prediction of benefit.

In our study, the correlation between LDL cholesterol reduction and 10-year ASCVD reduction was significant in the elderly (65-74 years of age) but not in the very elderly ( $\geq 75$ years of age). The 10-year ASCVD reduction in the very elderly group was overestimated because we counted patients aged $>79$ years as 79 years old due to the online ASCVD calcu- 
lator upper age limitation of 79 years. The real reduction rate should be lower than that we have shown. The LIPID trial, which was a large trial involving more than 9,000 participants, showed similar results that total and cardiovascular mortality in the pravastatin groups was significantly reduced up to 69 years of age, but there was no significant change in the groups aged 70 years and older [27]. The result of our study totally meets that of some present studies. "Age" was the major factor of cardiovascular risk, thus the benefit of high-intensity statin for lowering LDL cholesterol was limited to reduce cardiovascular risk in very elderly patients over 75 years old.

Statin-related ADRs should also be considered in elderly patients. There were some conflicting results reported. Elderly patients were vulnerable to ADRs because body size (muscle mass) or liver or renal function was reduced and the increased risk was 1.8 times higher [28]. However, in the CARDS study, the adverse event rate was similar compared to those younger than 65 years [29]. In our study, the ADR rate was higher in the very elderly group than in the elderly group. Especially the incidence of new-onset diabetes was high in the very elderly group, although the cause response with statins in not clear. This finding has important implications, because previous studies also suggested that statin therapy was associated with a $9 \%$ risk of new-onset diabetes mellitus which is higher in the elderly [30].

This study has several limitations. The present study was a retrospective study using an electronic medical record database with no outcome data available. The analysis was done based on prescription data, but we could not be sure whether the medications were taken as prescribed. The incidence of side effects was obtained by medical chart review, which could be underestimated. In addition, patient adherence may substantially affect the results. The less clear dose response between statin therapy and LDL reduction in the very elderly group may partly be due to poor adherence. We investigated the effect of statin treatment by using the 10-year ASCVD risk score as a surrogate marker of cardiovascular risk reduction. We approached the risk calculation in the very elderly population by counting the age as 79 years if the patients were older than 79 years. Because the pooled cohort equations are not recommended to inform cardiovascular risk for those $>75$ years of age, the adequacy of risk calculation for the very elderly population using the ASCVD risk score cannot be justified, even if there were no standard calculation tools for the very elderly population.

In conclusion, the elderly group over 65 years old showed a significant reduction in LDL cholesterol and 10-year ASCVD risk after statin therapy, but the incidences of ADR were higher in the high-intensity statin and very elderly group over 75 years old in spite of the benefit of reducing higher LDL cholesterol through high-intensity statins in the very elderly group. Therefore, the stepwise intensification of statin therapy might be recommended for very elderly patients $>75$ years old.

\section{References}

1 Castelli WP: Epidemiology of coronary heart disease: the Framingham study. Am J Med 1984;76:4-12.

-2 Lee HY, Park JB: The Korean Society of Hypertension Guidelines for the Management of Hypertension in 2013: its essentials and key points. Pulse (Basel) 2015;3:21-28.

-3 Anderson KM, Castelli WP, Levy D: Cholesterol and mortality. 30 years of follow-up from the Framingham study. JAMA 1987;257:2176-2180.

4 Randomised trial of cholesterol lowering in 4,444 patients with coronary heart disease: the Scandinavian Simvastatin Survival Study (4S). Lancet 1994;344:1383-1389.

5 Shepherd J, Cobbe SM, Ford I, Isles CG, Lorimer AR, MacFarlane PW, McKillop JH, Packard CJ: Prevention of coronary heart disease with pravastatin in men with hypercholesterolemia. West of Scotland Coronary Prevention Study Group. N Engl J Med 1995;333:1301-1307.

6 Jones PH: Statins as the cornerstone of drug therapy for dyslipidemia: monotherapy and combination therapy options. Am Heart J 2004;148:S9-S13. 
Lee et al.: High-Intensity Statin Therapy Is "Too Much," Thus Not Indicated for Very Elderly Patients

7 Park GM, Kim YH: Model for predicting cardiovascular disease: insights from a Korean cardiovascular risk model. Pulse (Basel) 2015;3:153-157.

-8 Cecelja M, Chowienczyk P: Molecular mechanisms of arterial stiffening. Pulse (Basel) 2016;4:43-48.

-9 Expert Panel on Detection, Evaluation, and Treatment of High Blood Cholesterol in Adults: Executive Summary of the Third Report of the National Cholesterol Education Program (NCEP) Expert Panel on Detection, Evaluation, and Treatment of High Blood Cholesterol In Adults (Adult Treatment Panel III). JAMA 2001;285:24862497.

10 European Association for Cardiovascular Prevention \& Rehabilitation, Reiner Z, Catapano AL, De Backer G, Graham I, Taskinen MR, Wiklund O, Agewall S, Alegria E, Chapman MJ, Durrington P, Erdine S, Halcox J, Hobbs R, Kjekshus J, Filardi PP, Riccardi G, Storey RF, Wood D; ESC Committee for Practice Guidelines (CPG) 20082010 and 2010-2012 Committees: ESC/EAS Guidelines for the management of dyslipidaemias: the Task Force for the management of dyslipidaemias of the European Society of Cardiology (ESC) and the European Atherosclerosis Society (EAS). Eur Heart J 2011;32:1769-1818.

11 Goff DC Jr, Lloyd-Jones DM, Bennett G, Coady S, D’Agostino RB, Gibbons R, Greenland P, Lackland DT, Levy D, O’Donnell CJ, Robinson JG, Schwartz JS, Shero ST, Smith SC Jr, Sorlie P, Stone NJ, Wilson PW, Jordan HS, Nevo L, Wnek J, Anderson JL, Halperin JL, Albert NM, Bozkurt B, Brindis RG, Curtis LH, DeMets D, Hochman JS, Kovacs RJ, Ohman EM, Pressler SJ, Sellke FW, Shen WK, Smith SC Jr, Tomaselli GF; American College of Cardiology/ American Heart Association Task Force on Practice Guidelines: 2013 ACC/AHA guideline on the assessment of cardiovascular risk: a report of the American College of Cardiology/American Heart Association Task Force on Practice Guidelines. Circulation 2014;129:S49-S73.

12 Pencina MJ, Navar-Boggan AM, D’Agostino RB Sr, Williams K, Neely B, Sniderman AD, Peterson ED: Application of new cholesterol guidelines to a population-based sample. N Engl J Med 2014;370:1422-1431.

13 Stone NJ, Robinson JG, Lichtenstein AH, Bairey Merz CN, Blum CB, Eckel RH, Goldberg AC, Gordon D, Levy D, Lloyd-Jones DM, McBride P, Schwartz JS, Shero ST, Smith SC Jr, Watson K, Wilson PW; American College of Cardiology/American Heart Association Task Force on Practice Guidelines: 2013 ACC/AHA guideline on the treatment of blood cholesterol to reduce atherosclerotic cardiovascular risk in adults: a report of the American College of Cardiology/American Heart Association Task Force on Practice Guidelines. J Am Coll Cardiol 2014; 63:2889-2934.

14 Go AS, Mozaffarian D, Roger VL, Benjamin EJ, Berry JD, Borden WB, Bravata DM, Dai S, Ford ES, Fox CS, Franco S, Fullerton HJ, Gillespie C, Hailpern SM, Heit JA, Howard VJ, Huffman MD, Kissela BM, Kittner SJ, Lackland DT, Lichtman JH, Lisabeth LD, Magid D, Marcus GM, Marelli A, Matchar DB, McGuire DK, Mohler ER, Moy CS, Mussolino ME, Nichol G, Paynter NP, Schreiner PJ, Sorlie PD, Stein J, Turan TN, Virani SS, Wong ND, Woo D, Turner MB; American Heart Association Statistics Committee and Stroke Statistics Subcommittee: Heart disease and stroke statistics - 2013 update: a report from the American Heart Association. Circulation 2013; 127:e6-e245.

15 Bays H, Cohen DE, Chalasani N, Harrison SA; The National Lipid Association's Statin Safety Task Force: An assessment by the Statin Liver Safety Task Force: 2014 update. J Clin Lipidol 2014;8:S47-S57.

16 Rosenson RS, Baker SK, Jacobson TA, Kopecky SL, Parker BA; The National Lipid Association's Muscle Safety Expert Panel: An assessment by the Statin Muscle Safety Task Force: 2014 update. J Clin Lipidol 2014;8:S58S71.

17 Maki KC, Ridker PM, Brown WV, Grundy SM, Sattar N; The Diabetes Subpanel of the National Lipid Association Expert Panel: An assessment by the Statin Diabetes Safety Task Force: 2014 update. J Clin Lipidol 2014;8:S17S29.

18 National Cholesterol Education Program (NCEP) Expert Panel on Detection, Evaluation, and Treatment of High Blood Cholesterol in Adults (Adult Treatment Panel III): Third Report of the National Cholesterol Education Program (NCEP) Expert Panel on Detection, Evaluation, and Treatment of High Blood Cholesterol in Adults (Adult Treatment Panel III) final report. Circulation 2002;106:3143-3421.

$\checkmark 19$ Lee PY, Alexander KP, Hammill BG, Pasquali SK, Peterson ED: Representation of elderly persons and women in published randomized trials of acute coronary syndromes. JAMA 2001;286:708-713.

20 Karmali KN, Goff DC Jr, Ning H, Lloyd-Jones DM: A systematic examination of the 2013 ACC/AHA pooled cohort risk assessment tool for atherosclerotic cardiovascular disease. J Am Coll Cardiol 2014;64:959-968.

21 Morgan TK, Williamson M, Pirotta M, Stewart K, Myers SP, Barnes J: A national census of medicines use: a 24-hour snapshot of Australians aged 50 years and older. Med J Aust 2012;196:50-53.

22 Sung J, Kim SH, Song HR, Chi MH, Park JE: Lipid-lowering treatment practice patterns in Korea: comparison with the data obtained from the CEPHEUS Pan-Asian study. J Atheroscler Thromb 2014;21:1219-1227.

-23 Ridker PM, Danielson E, Fonseca FA, Genest J, Gotto AM Jr, Kastelein JJ, Koenig W, Libby P, Lorenzatti AJ, MacFadyen JG, Nordestgaard BG, Shepherd J, Willerson JT, Glynn RJ, Group JS: Rosuvastatin to prevent vascular events in men and women with elevated C-reactive protein. N Engl J Med 2008;359:2195-2207.

24 Chokshi NP, Messerli FH, Sutin D, Supariwala AA, Shah NR: Appropriateness of statins in patients aged $\geq 80$ years and comparison to other age groups. Am J Cardiol 2012;110:1477-1481.

25 Wilmot KA, Khan A, Krishnan S, Eapen DJ, Sperling L: Statins in the elderly: a patient-focused approach. Clin Cardiol 2015;38:56-61. 
Lee et al.: High-Intensity Statin Therapy Is "Too Much," Thus Not Indicated for Very Elderly Patients

-26 Cholesterol Treatment Trialists' (CTT) Collaboration, Baigent C, Blackwell L, Emberson J, Holland LE, Reith C, Bhala N, Peto R, Barnes EH, Keech A, Simes J, Collins R: Efficacy and safety of more intensive lowering of LDL cholesterol: a meta-analysis of data from 170,000 participants in 26 randomised trials. Lancet 2010;376: 1670-1681.

27 Long-Term Intervention with Pravastatin in Ischaemic Disease (LIPID) Study Group: Prevention of cardiovascular events and death with pravastatin in patients with coronary heart disease and a broad range of initial cholesterol levels. N Engl J Med 1998;339:1349-1357.

28 Egger SS, Ratz Bravo AE, Hess L, Schlienger RG, Krahenbuhl S: Age-related differences in the prevalence of potential drug-drug interactions in ambulatory dyslipidaemic patients treated with statins. Drugs Aging 2007; 24:429-440.

29 Colhoun HM, Betteridge DJ, Durrington PN, Hitman GA, Neil HA, Livingstone SJ, Thomason MJ, Mackness MI, Charlton-Menys V, Fuller JH; CARDS investigators: Primary prevention of cardiovascular disease with atorvastatin in type 2 diabetes in the Collaborative Atorvastatin Diabetes Study (CARDS): multicentre randomised placebo-controlled trial. Lancet 2004;364:685-696.

30 Sattar N, Preiss D, Murray HM, Welsh P, Buckley BM, de Craen AJ, Seshasai SR, McMurray JJ, Freeman DJ, Jukema JW, Macfarlane PW, Packard CJ, Stott DJ, Westendorp RG, Shepherd J, Davis BR, Pressel SL, Marchioli R, Marfisi RM, Maggioni AP, Tavazzi L, Tognoni G, Kjekshus J, Pedersen TR, Cook TJ, Gotto AM, Clearfield MB, Downs JR, Nakamura H, Ohashi Y, Mizuno K, Ray KK, Ford I: Statins and risk of incident diabetes: a collaborative meta-analysis of randomised statin trials. Lancet 2010;375:735-742. 